\title{
The impacts of wind technology advancement on future global energy
}

\author{
Xiaochun Zhang a,b,*, Chun Ma ${ }^{\mathrm{a}, \mathrm{b}}$, Xia Song ${ }^{\mathrm{a}}$, Yuyu Zhou ${ }^{\mathrm{c}}$, Weiping Chen ${ }^{\mathrm{d}}$ \\ ${ }^{a}$ Ecological Modeling And Integration Laboratory, San Diego State University, San Diego, CA 92182, United States \\ ${ }^{\mathrm{b}}$ Department of Global Ecology, Carnegie Institution for Science, Stanford, CA 94305, United States \\ ${ }^{\mathrm{c}}$ Department of Geological and Atmospheric Sciences, Iowa State University, Ames, IA 50011, United States \\ ${ }^{\mathrm{d}}$ State Key Laboratory of Urban and Regional Ecology, Research Center for Eco-Environmental Sciences, Chinese Academy of Sciences, Beijing 100085, PR China
}

\section{H I G H L I G H T S}

- Integrated assessment model perform a series of scenarios of technology advances.

- Explore the potential roles of wind energy technology advance in global energy.

- Technology advance impacts on energy consumption and global low carbon market.

- Technology advance influences on global energy security and stability.

\section{A R T I C L E I N F O}

\section{Article history:}

Received 11 February 2016

Received in revised form 5 April 2016

Accepted 9 April 2016

Available online 26 April 2016

\section{Keywords:}

Electricity generation

Wind energy

GHG mitigation

Electricity cost

Energy security

\begin{abstract}
A B S T R A C T
To avoid additional global warming and environmental damage, energy systems need to rely on the use of low carbon technologies like wind energy. However, supply uncertainties, production costs, and energy security are the main factors considered by the global economies when reshaping their energy systems. Here, we explore the potential roles of wind energy technology advancement in future global electricity generations, costs, and energy security. We use an integrated assessment model performing a series of technology advancement scenarios. The results show that double of the capital cost reduction causes $40 \%$ of generation increase and $10 \%$ of cost decrease on average in the long-term global wind electricity market. Today's technology advancement could bring us the benefit of increasing electricity production in the future $40-50$ years, and decreasing electricity cost in the future 90-100 years. The technology advancement of wind energy can help to keep global energy security and stability. An aggressive development and deployment of wind energy could in the long-term avoid $1 / 3$ of gas and $1 / 28$ of coal burned, and keep $1 / 2$ biomass and $1 / 20$ nuclear fuel saved from the global electricity system. The key is that wind resources are free and carbon-free. The results of this study are useful in broad coverage ranges from innovative technologies and systems of renewable energy to the economic industrial and domestic use of energy with no or minor impact on the environment.
\end{abstract}

(c) 2016 Elsevier Ltd. All rights reserved.

\section{Introduction}

Nations around the world work on generating more energy from renewable resources and transitioning into energy systems to mitigate climate change and environmental degradation. Globally, renewable energy accounted for $19 \%$ of the energy consumption in 2012 and 22\% of the electricity generation in 2013 [1], respectively. In more than 30 countries, renewable energy takes more than $20 \%$ of the energy supply. Global investment in

\footnotetext{
* Corresponding author at: Ecological Modeling And Integration Laboratory, San Diego State University, San Diego, CA 92182, United States.

E-mail addresses: xczhang@mail.sdsu.edu, xczhang@carnegiescience.edu (X. Zhang).
}

renewable energies is more than 214 billion USD in 2013 [2]. Renewable energy markets are believed to continue rapidly grow in future decades [2].

Wind power has been seen as an important alternative to fossil fuels $[3,4]$. Studies focus on policy, technology, development and demonstration of wind energy system and their role on mitigation of environmental pollutants [5-10]. As an important renewable energy source, wind energy exists over wide areas and is seen as a way to limit greenhouse gas emissions to avoid the global warming threshold [11,12]. Internationally, there is strong support for promoting wind power [13]. At the end of 2014, the global cumulative installed capacity of wind power is $369,553 \mathrm{MW}$, which has increased 16\% compared to 2013 [14]. Continuous development and deployment of wind energy helps climate 
mitigation, economic benefits, and energy security [15]. The longterm global technical potential of wind energy is believed to be five times the total current global energy production, or 40 times the current electricity demand, assuming all practical barriers needed were overcome [16]. What is more, supply uncertainties, costs of production, and energy security are the main concerns of current energy systems by the global economies [17]. There is no doubt that the technology advancement of wind energy could help reduce the costs of wind electricity generation construction and operation. It is important to understand how technology advancement would influence the global wind electricity production as well as energy system security and stability.

This study focuses on the impacts of wind technology on the future global energy. The purposes of this research are to study (1) the impacts of timescales on marginal effects of global wind electricity production to technology advancement; (2) the sensitivity of electricity costs to the change of capital costs; and (3) the impacts of wind energy development and deployment on energy system security and stability. The findings help to improve our understanding on the sensitivity of the future global electricity generation and costs to the technology advancement. The results could be helpful for the renewable energy studies, especially in the areas of the optimal use of energy resources, optimization of energy processes, mitigation of environmental pollutants, and sustainable energy systems.

\section{Methodology}

\subsection{Model development for technology advancement}

In this study, the technology advancement is represented by overnight capital cost (OCC) change. OCC is a typical parameter that is used in the power generation industry to describe the cost of building a power plant overnight [18]. OCC is useful to compare the economic feasibility of building plants with various technologies or technology advancement. OCC is also a parameter to represent technology, and does not take into account financing costs, and hence is not an actual estimate of construction cost.

If the OCC reduces from $C 0 \$ / \mathrm{kW}$ at year $y r 0$ to $C 1 \$ / \mathrm{kW}$ at year $y r 1$ with annual change rate $r$ per year, then

$C_{1}=C_{0}(1-r)^{(y r 1-y r 0)}$

Annual OCC change rate $(r)$ is

$r=1-\left(C_{1} / C_{0}\right)^{1 /(y r 1-y r 0)}$.

\subsection{Simulation scenarios and data}

We use the Global Climate Assessment Model (GCAM4.0) to do the simulation in this study. The model is a partial equilibrium model where economy, energy, agriculture, and land-use systems are modeled in an integrated framework (http://wiki.umd.edu/ gcam).

We use the annual OCC change rate from year 2005 to year 2010 as the rate of business-as-usual $\left(r_{B A U}\right)$, and the year 2010 as the baseline year for the simulation to the year of 2100 . The parametrized XML file with OCC for GCAM in BAU scenario is shown in supplement. is

In a scenario, if annual OCC change rate is $\alpha$ times of $r_{B A U}$, then $r$

$r=\alpha r_{B A U}$

We evaluate global total electricity generation and mean cost in this study.

\subsection{Sensitivity analysis}

We consider the sensitivity of global wind electricity generation and cost to the technology advancement. In this study, we use annual OCC change rates $(r)$ to measure technology advancement. The considered OCC change rates are from 1 to 10 times of annual OCC change rate as business-as-usual $\left(r_{B A U}\right)[3,4,6]$. The baseline year of the simulation is 2010. Time horizons are near-term (2020), middle-term (2050) and long-term (2100).

\section{Results and discussion}

\subsection{Impact on global wind electricity production}

The technology advancement of wind energy impacts global wind electricity production (Figs. 1 and 2 ).

Fig. 1 illustrates the sensitivity of global wind electricity generation to the technology advancement when the annual overnight capital cost (OCC) change rate increase 1-10 times.

In the near term (2020), the global wind electricity generation (WEG) increases $19.5 \%$ on average for every additional increment of $r$ (average marginal sensitivity). In the middle term (2050) and the long term (2100), the marginal sensitivities are $30.0 \%$ and 18.7\%. In the middle term (2050), the first additional $r$ increase causes $42.5 \%$ of WEG increments (first marginal sensitivity). Then this number decreases for every additional $r$ increase. In the long term (2100), there is a similar result with that of the middle term. The first marginal sensitivity is $59.2 \%$. The marginal sensitivities are smaller than $10 \%$ after the 6 th increment of OCC change rates.

Fig. 2 shows the change of absolute values of global wind electricity generation under different annual capital cost change rate. The wind electricity generation is $\sim 1.23 \mathrm{EJ}$ in based year 2010 . With annual capital cost change rate of business as usual (BAU), the global wind electricity generation is evaluated to be $\sim 5.0 \mathrm{EJ}$ in 2020, $\sim 17 \mathrm{EJ}$ in 2050 , and $\sim 40 \mathrm{EJ}$ in 2100 . If the rate is double, wind electricity generation expands rapidly to $\sim 63 \mathrm{EJ}$ in 2100 , which is $58 \%$ more than that of BAU scenario.

With the technology advancement, the wind electricity generation has increased $27 \%$ in 2007 [19]. Since then, the wind electricity became an important part in the global energy markets with 36 billion USD of annual additional installed generating equipment [19]. In reality, the wind electricity generation may fluctuate with global economic situations and policy options, such as the wind electricity generation that was affected by the 20092010 global financial crisis as well as other renewable energy industries. However, the wind electricity has 28\% annual growth of new installations over the last five years, and wind electricity is projected to be $8 \%$ of global electricity market by 2018 [20].

In this study, we find that current technology advancement of wind energy could get the high benefit of increasing electricity production in future $40-50$ years. The marginal electricity production declines with the technology advancement increase, i.e., for the same amount of capital cost reduction (due to technology advancement), the first reduction could help to generate more electricity than the second. The earlier the investment on wind energy development is, the more benefits could be received from the increased wind electricity generation.

\subsection{Impact on global wind electricity economics}

We also consider the technology advancement of wind energy impacts on global wind electricity economics (Figs. 3 and 4).

Fig. 3 illustrates the sensitivity of global wind electricity economics to the technology advancement. In the near term (2020), the average marginal global electricity cost to capital cost 


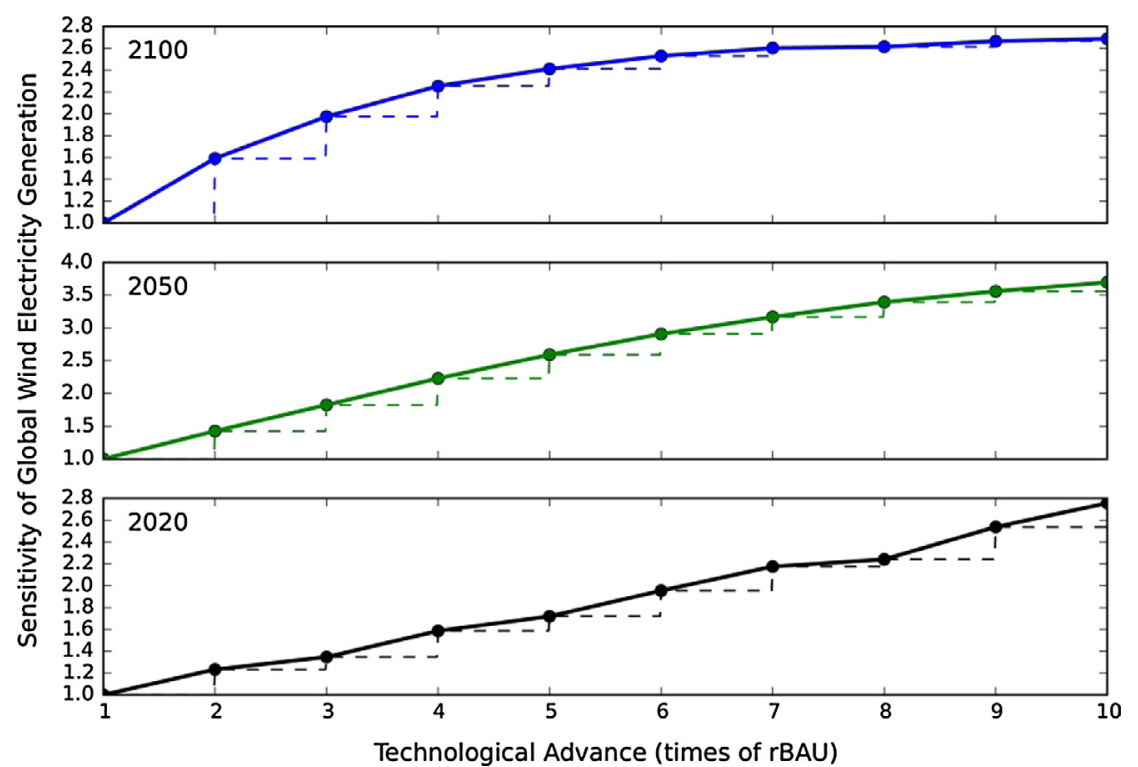

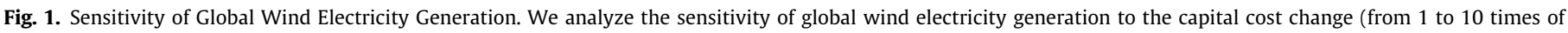

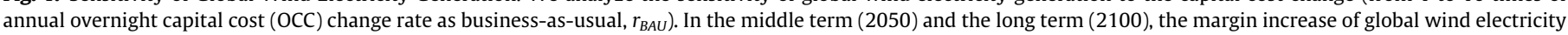

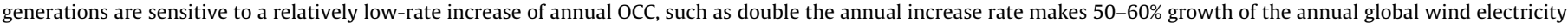
generation. However, low sensitivity could be from a relatively high increase of annual occ, such as sevenfold in the middle term, and fivefold in the long term.

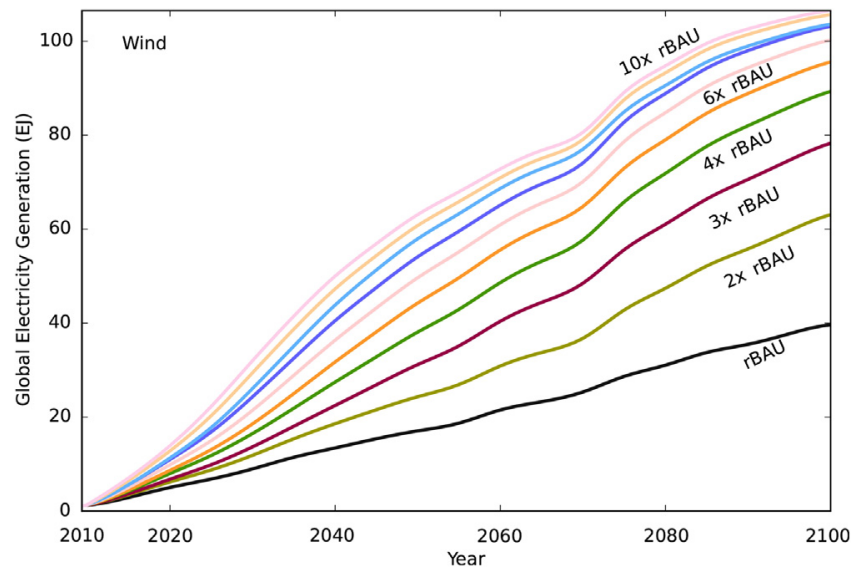

Fig. 2. Sensitivity of Global Wind Electricity Generation. Time series of global wind electricity generation on different scenarios are shown in this figure.

is $-3.0 \%$, and the first marginal sensitivity is $-3.8 \%$. In the middle term (2050), the average marginal electricity cost is $-3.8 \%$, and the first marginal electricity cost is $-11.0 \%$. In the long term (2100), the average marginal electricity cost is $-2.6 \%$, and the first marginal sensitivity is $-12.6 \%$. The first marginal decrease of capital cost is more effective than subsequent marginal decreases to reduce global wind electricity costs for either near, middle, or long term.

Fig. 4 shows time series of the estimated global wind electricity cost changes from 2010 to 2100. The wind electricity cost is 27.5 USD per GJ (i.e., 9.9 UScents per kW h; Fig. S2) in 2010 which is the base year in this study. On the BAU scenario, the cost of wind electricity costs are 31.6 USD per GJ (11.4 UScents per $\mathrm{kWh}$ ) in year 2020, 31.1 USD per GJ (11.2 UScents per $\mathrm{kW} \mathrm{h}$ ) in year 2050, and 28.6 USD per GJ (10.3 UScents per $\mathrm{kWh}$ ) in year 2100. With the capital cost with annual decrease rate as 10 times of $r_{B A U}$, the cost of wind electricity costs are 23.1 USD per GJ (8.3 UScents per $\mathrm{kW} \mathrm{h}$ ) in year 2020, 20.5 USD per GJ (7.4 UScents per kW h) in year 2050, and 22.0 USD per GJ (7.9 UScents per $\mathrm{kW} \mathrm{h}$ ) in year 2100.

Wind power is capital intensive, instead of fuel-cost intensive [21]. The estimation of wind electricity cost includes the cost of turbine construction, cost of transmission facilities, lifetime of equipment, potential electricity generation, and other factors. Most of the factors are technology-dependent.

With the technology advancement throughout the world, the wind electricity cost is going down. The cost of wind electricity in 2004 is about 20\% that of in 1980 [22]. In 2010, the wind electricity costs matched electricity costs from traditional energy sources in the Europe Union [23].

The wind electricity costs in some developed countries might be even lower than the estimated global average costs. In 2010, the costs of onshore and offshore wind electricity are 8.0-10 pence per $\mathrm{kW} h$ (about 12.4-15.5 UScents per $\mathrm{kW} \mathrm{h}$ ) and 15-21 pence per $\mathrm{kW}$ h (about 23.3-32.5 UScents per $\mathrm{kW} \mathrm{h}$ ) in the United Kingdom [24]. In 2011, onshore wind electricity cost is 6.9 euro cents per $\mathrm{kWh}(\sim 9.6$ UScents per $\mathrm{kWh})$ in French [25]. In 2013, the costs of onshore and offshore wind electricity are 4.5-10.7 euro cents per $\mathrm{kWh}$ (about 5.9-14.1 UScents per $\mathrm{kWh}$ ) and 11.9-19.4 euro cents per $\mathrm{kWh}$ (about 15.7-25.6 UScents per $\mathrm{kWh}$ ) in Germany [26].

In this study, we find that current technology advancement of wind energy could benefit decreasing electricity costs in the future 90-100 years. The marginal electricity cost declines with the technology advancement increase. For the same amount of capital cost reduction, the first reduction could help to get lower electricity cost than the second. The earlier we invest on wind energy development, the earlier benefits could be received from decreased wind electricity cost.

\subsection{Impacts on global energy security and stability}

We also consider the impacts of wind energy development on the global energy security and stability. A common recognition is that an economy should diversify energy systems and develop domestic energy sources, so that the economy could supply their economy development with higher energy security and stability. 


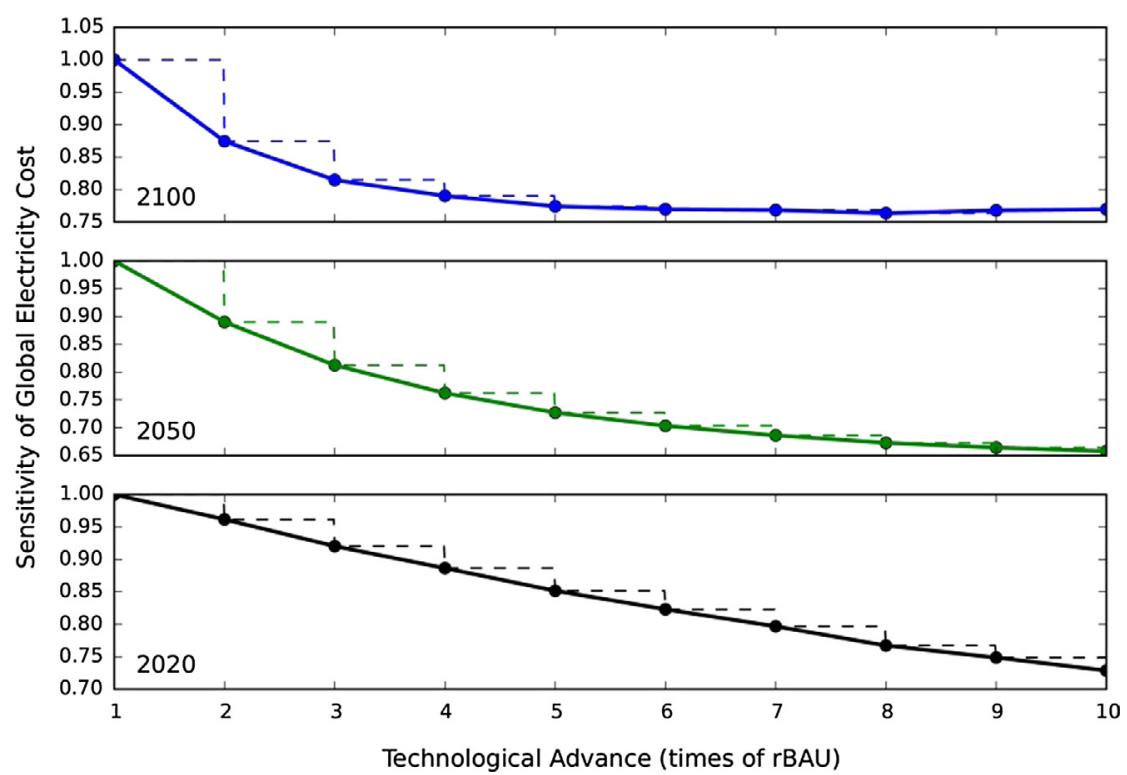

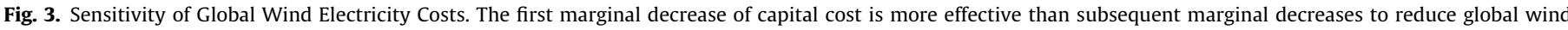
electricity costs for near, middle, or long term.

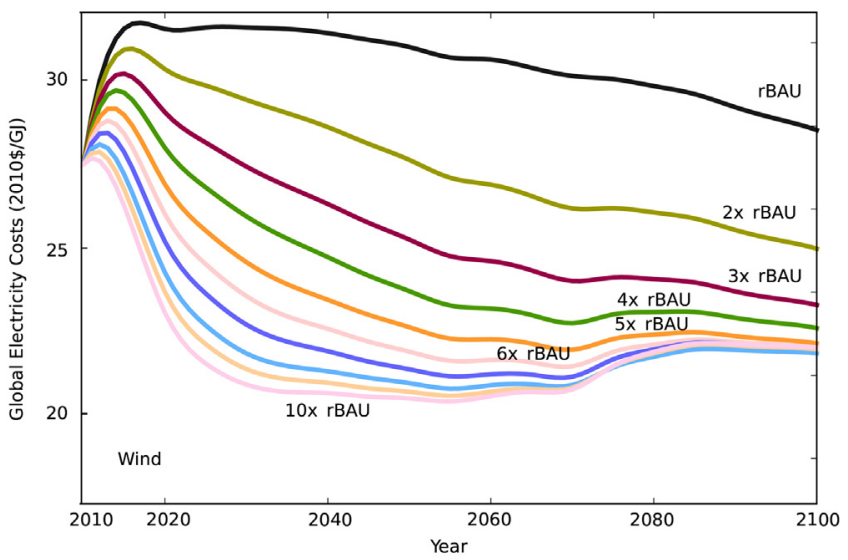

Fig. 4. Sensitivity of global wind electricity costs. Time series of global wind electricity cost is sensitive on different scenarios.

Fig. 5 shows that, at year 2100, the global total electricity generation is $332.0 \mathrm{EJ}$ on BAU scenario, and $356.8 \mathrm{EJ}$ in $10 \times r_{B A U}$ scenario which annual overnight capital cost change rate is 10 times that of BAU. Wind energy takes $11.9 \%$ of global total electricity generation under BAU, and $29.9 \%$ on $10 \times r_{B A U}$ scenario. From BAU to scenario $10 \times r_{B A U}$, coal based electricity decreases from 97.1 EJ to 93.7 EJ at year 2100; Oil electricity decreases from 2.14 EJ to 2.12 EJ; Gas based electricity decreases from $48.5 \mathrm{EJ}$ with BAU to $34.4 \mathrm{EJ}$ with $10 \times r_{B A U}$; Biomass electricity decreases from 13.6 EJ with BAU to $6.9 \mathrm{EJ}$ with $10 \times r_{B A U}$; Nuclear electricity decreases from 61.0 EJ with BAU to $58.1 \mathrm{EJ}$ with $10 \times r_{B A U}$; Geothermal electricity decreases from 3.4 EJ with BAU to $2.9 \mathrm{EJ}$ with $10 \times r_{B A U}$; Solar energy decreases from $32.5 \mathrm{EJ}$ with BAU to $30.7 \mathrm{EJ}$ with $10 \times r_{B A U}$. With a high wind technology advancement, the total electricity generation is increased and electricity generations by other technologies are almost decreased. For results of other scenarios $\left(2 \times r_{B A U}\right.$ to $\left.9 \times r_{B A U}\right)$, please see Fig. $S 1$.

The price of wind energy is relatively stable and predictable because wind is a free energy source, and there is no fuel cost for wind electricity if the facility operates well [27]. In contrast, the
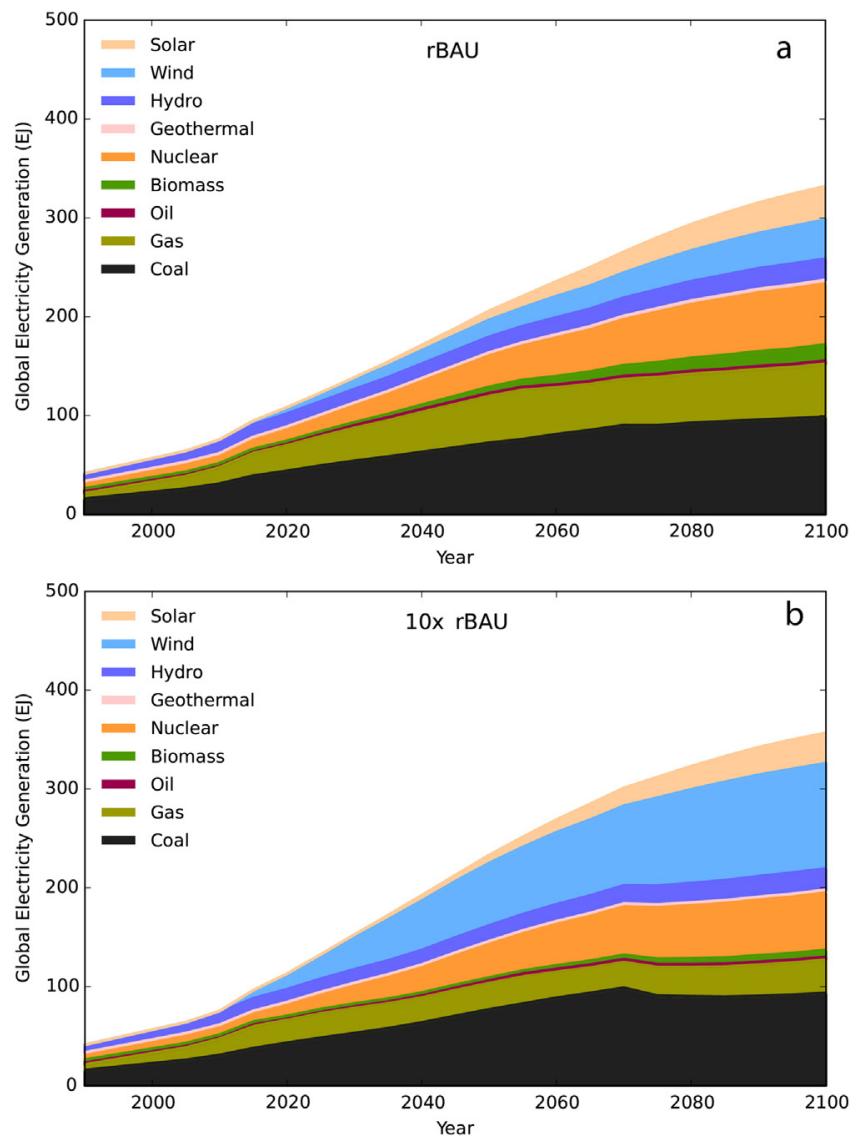

Fig. 5. Sensitivity of Global Electricity Generation System to Wind Energy Technology Advancement. This figure shows (a) the business-as-usual BAU scenario and (b) the $10 \times r_{B A U}$ scenario.

prices of natural gas electricity are instable and not easy to predict because the cost of fuel is a large part of the cost of gas electricity [28]. Natural gas is seen as a bridge fuel to clean energy, however, the natural gas leakage and its delay of near-zero energy systems 
could offset its climate benefits [29-32]. The high uncertainty of gas and other fossil fuel price reduces the security and stability of electricity supply and then impacts the economy [33]. Air pollutants emitted from fossil fuel, such as particular matters [34-36] and carbon emission [37], also cause environmental and climatic risks [38,39]. The well-known examples are the 1973-1974 Arab oil embargo and the 2000-2001 California electricity crisis. Our results show that wind technology advancement would increase $160 \%$ of wind electricity generation, and decrease $30 \%$ of gas based electricity in long term (Fig. 5 and Fig. S1).

In this study, we show that technology advancement could help improve global energy security and stability.

\section{Conclusion}

This study has focused on impacts of wind technology on global future energy. Based on the existing knowledge, we use an integrated assessment model approach to evaluate the productions, costs and energy security issues of technology advancement for wind energy in the future untill 2100. Specifically, we investigate the sensitivity of wind electricity generations, wind electricity costs and energy system security to the capital cost changes of wind energy, which is used to compare the economic feasibility of building plants with various technology changes. We find that doubling the change rate of annual capital cost makes $40 \%$ of generation increase and $10 \%$ of cost decrease of wind electricity on average in about at least 100 years. Current technology advancement of wind energy could get the benefit of increasing electricity production in the future $40-50$ years, and the benefit of decreasing electricity cost in the future 90-100 years. The technology advancement could help improve global energy security and stability.

The study could bridge the gaps between research, development and implementation of wind energy. The results of this study are useful in broad coverage ranges from innovative technologies and systems of renewable energy to the economic industrial and domestic use of energy, with no or minor impacts on the environment. The study is also helpful with solving problems of modeling and forecasting, conservation strategies, and the environmental, social and economic impacts of energy policies and usage, including climate change mitigation and environmental pollution reduction.

\section{Appendix A. Supplementary material}

Supplementary data associated with this article can be found, in the online version, at http://dx.doi.org/10.1016/j.apenergy.2016. 04.029.

\section{References}

[1] UNEP. Renewables 2014: Global Status Report 2014

[2] Ellabban O, Abu-Rub H, Blaabjerg F. Renewable energy resources: current status, future prospects and their enabling technology. Renew Sustain Energy Rev 2014:39:748-64.

[3] IEA. Technology roadmap wind energy. IEA Technology Roadmaps. Paris: OECD Publishing; 2015. http://dx.doi.org/10.1787/9789264238831-en.

[4] Zhao H, Wu Q, Hu S, Xu H, Rasmussen CN. Review of energy storage system for wind power integration support. Appl Energy 2015;137:545-53.

[5] Foley AM, Leahy PG, Li K, McKeogh EJ, Morrison AP. A long-term analysis of pumped hydro storage to firm wind power. Appl Energy 2015;137:638-48.
[6] Xiao Y, Wang X, Wang X, Dang C, Lu M. Behavior analysis of wind power producer in electricity market. Appl Energy 2016;171:325-35.

[7] Fant C, Gunturu B, Schlosser A. Characterizing wind power resource reliability in southern Africa. Appl Energy 2016;161:565-73.

[8] Gielen D, Boshell F, Saygin D. Climate and energy challenges for materials science. Nat Mater 2016;15:117-20.

[9] Yang A-S, Su Y-M, Wen C-Y, Juan Y-H, Wang W-S, Cheng C-H. Estimation of wind power generation in dense urban area. Appl Energy 2016;171:213-30.

[10] Fast S, Mabee W, Baxter J, Christidis T, Driver L, Hill S, et al. Lessons learned from Ontario wind energy disputes. Nat Energy 2016;1:15028.

[11] Barthelmie RJ, Pryor SC. Potential contribution of wind energy to climate change mitigation. Nat Clim Change 2014;4:684-8. http://dx.doi.org/10.1038/ nclimate2269.

[12] Jacobson MZ. Energy modelling: clean grids with current technology. Nat Clim Change 2016.

[13] UNEP. Global trends in sustainable energy investment: analysis of trends and issues in the financing of renewable energy and energy efficiency in OECD and developing countries. United Nations Environment Programme; 2014.

[14] GWEC. Global Wind Statistics 2014. Global Wind Energy Council; 2014.

[15] IEA. Energy Technology Perspectives. International Energy Agency; 2014.

[16] Archer CL, Jacobson MZ. Spatial and temporal distributions of US winds and wind power at $80 \mathrm{~m}$ derived from measurements. J Geophys Res Atmos $2003 ; 108$.

[17] Asif M, Muneer T. Energy supply, its demand and security issues for developed and emerging economies. Renew Sustain Energy Rev 2007;11:1388-413.

[18] Gumerman E, Marnay C. Learning and cost reductions for generating technologies in the National Energy Modeling System (NEMS). Ernest Orlando Lawrence Berkeley National Laboratory; 2004.

[19] GWEC. Continuing boom in wind energy - 20 GW of new capacity in 2007. Global Wind Energy Council; 2008.

[20] Forsyth T. International investment and climate change: energy technologies for developing countries. Routledge; 2014.

[21] Dolf Gielen. Renewable energy technologies: cost analysis series. International Renewable Energy Agency; 2013.

[22] Neij L. Cost development of future technologies for power generation-a study based on experience curves and complementary bottom-up assessments. Energy Policy 2008;36:2200-11. http://dx.doi.org/10.1016/i.enpol.2008.02. $\underline{029}$.

[23] Zhong H, Du P, Tang F, Wang L. Lagrangian dynamic large-eddy simulation of wind turbine near wakes combined with an actuator line method. Appl Energy 2015;144:224-33.

[24] Higgins P, Foley A. The evolution of offshore wind power in the United Kingdom. Renew Sustain Energy Rev 2014;37:599-612.

[25] Fürsch M, Hagspiel S, Jägemann C, Nagl S, Lindenberger D, Tröster E. The role of grid extensions in a cost-efficient transformation of the European electricity system until 2050. Appl Energy 2013;104:642-52.

[26] Heier S. Grid integration of wind energy: onshore and offshore conversion systems. John Wiley \& Sons; 2014.

[27] DeCarolis JF, Keith DW. The economics of large-scale wind power in a carbon constrained world. Energy Policy 2006;34:395-410.

[28] Zhu J. Optimization of power system operation. John Wiley \& Sons; 2014.

[29] Zhang X, Myhrvold NP, Caldeira K. Key factors for assessing climate benefits of natural gas versus coal electricity generation. Environ Res Lett 2014;9:114022.

[30] Zhang X, Myhrvold NP, Caldeira K. Evaluating the climate effects of natural gas vs coal electricity generation. Am Geophys Union Fall Meet 2014;GC13B:0625.

[31] Zhang X, Myhrvold NP, Caldeira K. Assessing climate benefits of natural gas and coal electricity generation. Proc Eur Geosci Union Gen Assem EGU2015. p. 13925.

[32] Zhang X, Myhrvold NP, Hausfather Z, Caldeira K. Climate benefits of natural gas as a bridge fuel and potential delay of near-zero energy systems. Appl Energy 2015.

[33] Borenstein S. The private and public economics of renewable electricity generation. National Bureau of Economic Research; 2011.

[34] Zhang X, Chen W, Ma C, Zhan S. Modeling particulate matter emissions during mineral loading process under weak wind simulation. Sci Total Environ 2013;449:168-73. http://dx.doi.org/10.1016/j.scitotenv.2013.01.050.

[35] Zhang X, Chen W, Ma C, Zhan S. Modeling the effect of humidity on the threshold friction velocity of coal particles. Atmos Environ 2012;56:154-60.

[36] Zhang X, Chen W, Ma C, Zhan S, Jiao W. Regional atmospheric environment risk source identification and assessment. Environ Sci 2012;33:4167-72.

[37] Zhang X, Caldeira K. Time scales and ratios of climate forcing due to thermal versus carbon dioxide emissions from fossil fuels. Geophys Res Lett 2015;42. http://dx.doi.org/10.1002/2015GL063514. 2015GL063514.

[38] Chingulpitak S, Wongwises S. Critical review of the current status of wind energy in Thailand. Renew Sustain Energy Rev 2014;31:312-8.

[39] Li C-B, Chen H-Y, Zhu J, Zuo J, Zillante G, Zhao Z-Y. Comprehensive assessment of flexibility of the wind power industry chain. Renew Energy 2015;74:18-26. 